\title{
Mirar el ÁRBOL Y VER EL BOSQUE UNA APROXIMACIÓN A LA EPISTEMOLOGÍA DE LAS RUINAS DE MARIO ORTIZ
}

\author{
Ignacio Barbeito
}

\section{UNA SERIE DE CUADERNOS}

Bajo la didáctica denominación Cuadernos de Lengua y Literatura, el poeta, crítico y narrador argentino Mario Ortiz (Bahía Blanca, 1965) publica desde el año 2000 una serie de libros que transita por géneros y registros en continua mudanza y contaminación recíproca. ${ }^{1}$ El conjunto textual lejos está de ordenarse según los propósitos de alguna pedagogía atenta a los requerimientos de una conveniente progresión en la enseñanza de los saberes; por el contrario, el lector tiene más bien la impresión de encontrarse ante un collage en el que los relatos se diversifican, las voces producen efectos de diseminación y los objetos aludidos perforan

\footnotetext{
${ }^{1}$ La serie de los Cuadernos de Lengua y Literatura se integra de la siguiente manera: Cuadernos de Lengua y Literatura. Volumen I (2000); Cuaderno de Lengua y Literatura. Volumen II (2001); Cuaderno de Lengua y Literatura. Volumen III: Yo, Luis Carapella (2003); Cuaderno de Lengua y Literatura. Volumen IV: El libro de las formas que se hunden (2010); Cuaderno de Lengua y Literatura. Volumen V: Al pie de la letra (2010); Cuaderno de Lengua y Literatura. Volumen VI: Crítica de la imaginación pura (2011); Cuaderno de Lengua y Literatura VII: Tratado de Fitolingüística; Cuadernos de Lengua y Literatura. Volumen VIII: Conectores temporales; Cuadernos de Lengua y Literatura. Volumen IX: Ejercicios de lectoescritura. En 2013, en Buenos Aires, la casa editora Eterna Cadencia publicó los volúmenes V, VI y VII en un mismo libro. Por otra parte, en 2015, con algunos agregados, la Editorial Hemisferio Derecho reunió para su publicación en un mismo libro los tres primeros volúmenes. También en 2015, en Córdoba, la Editorial miembro fantasma publicó La canción del poeta atrasado. Cuadernos de Lengua y Literatura Volumen 3 1⁄2.
} 
el presente, revelándose como umbrales de acceso a otras dimensiones temporales.

Con frecuencia, la crítica se refiere a los Cuadernos abordando a cada uno como parte de un conjunto mayor o expresión numeralmente secuenciada de un proyecto. Sin embargo, la premura por nombrar suscita equívocos profundos. Los Cuadernos no son parte de una totalidad preconcebida, cuyos contornos se desplegarían en sucesivas ediciones. En los Cuadernos no hay tampoco una intención organizadora a la que remitir el conjunto de las cosas escritas; y si por momentos los textos de Ortiz reunidos en los Cuadernos parecen sugerir otra cosa, pronto las palabras y las historias se superponen, se confunden y empujan al lector en direcciones inesperadas, nunca hacia un fin que sujete la dispersión de voces, personajes y relatos, pero tampoco la de géneros: la poesía, el ensayo, el tratado, el apunte de estudio, la autobiografía y la crónica, la lista de inventario, el prospecto farmacológico y el cuento, entre otros. En este sentido, podría atribuírsele al autor de los Cuadernos profesar que el fin último de la literatura no radica en la Obra sino en la disolución de toda tentativa que apunte a producirla: acaso, con modestia, ¿no es lo que conjetura Ortiz cuando escribe que el título Cuadernos de Lengua y Literatura "implica recordarse que uno no escribe una Obra, un libro unitario, sino apenas determinados ejercicios, exploraciones, tentativas (ORTIZ, 2013, p. 315)?

Es factible defender, entonces, que la denominación de cuadernos, empleada para reunir en una misma serie un conjunto de libros muy diferentes, porta la pretensión de operar como contrapunto (al menos enunciativo) con la inclinación a tratar a esos volúmenes como lo que comercialmente son, es decir, libros que conforman la obra de un autor: "Y además -escribe Ortiz al comenzar el octavo volumen-: esto apenas es un cuaderno de notas, registros de experimentación (...) Contra toda tentación de escribir libros" (ORTIZ, 2013, p. 10). Si al "libro" se asocian propiedades como las de lo ordenado y concluido, al "cuaderno" lo hacen las de lo ocasional y lo fragmentario, lo caprichoso incluso. Y mientras el libro persiste en ser considerado el umbral de existencia de la condición profesional del escritor, el waypoint de cualquier cartografía literaria y la mercancía insignia de la industria editorial, el cuaderno, en cambio, reserva para sí una polivalencia operativa solamente condicionada por la exigencia de hacer trazos sobre el papel. Así, y a diferencia del libro, el cuadernosueleserun espacio depruebas, esbozosy bocetos, deanotaciones 
circunstanciales, aunque a veces urgentes o imprescindibles; es también un espacio para la ejercitación personal, para registrar la apertura de posibles proyectos o los resultados periódicos de una exploración, para reunir apuntes de todo aquello que ha suscitado curiosidad e interés.

Resultaría propicio esclarecer en qué momento y en qué condiciones se borronearon las fronteras entre los textos y epitextos, permitiendo que los cuadernos de un escritor alcancen tanta dignidad literaria como la de sus libros, al punto de tornar obsoleta la distinción. Sin embargo, en el caso de Ortiz la evocación del cuaderno aparece vinculada a una experiencia para-literaria y de impronta estatal, la experiencia escolar, recreada en las primeras páginas del quinto volumen, aunque circunscripta fundamentalmente al aprendizaje de las letras. Transcurridos treinta y ocho años, el narrador refiere un encuentro entre Mario Ortiz y la maestra que en primer grado le enseñó el abecedario. En esa escena, la maestra insta a su antiguo alumno a detenerse en el tipo de letras con las que está escrito el título de un recorte periodístico de 1972, contra la tentación de aquél de interpretar el significado de cada una de las palabras. El sentido de la indicación de la maestra se torna una revelación para Ortiz, cuando ambos se detienen luego frente a un comercio y observan los cuerpos de las letras, erguidos sobre el alero que sobresale en el frente del edificio. Las letras anuncian el rubro y el nombre del comercio; pero también tienen masa, peso, volumen y densidad, ocupan un espacio, como los objetos y las personas, y en ellas se cifra el placer que de niño experimentaba Ortiz al manipular un juego de letras de plástico: "sorpresa, o al menos conmoción de espíritu por algo que viene a ocupar un espacio junto a nosotros" (ORTIZ, 2013, p. 34). Esta epojé que propone Ortiz -porque resulta vano desoír un eco del llamado de Husserl a volver a las cosas mismas- suspendiendo los significados para concentrarse en el ser de la letra le permite, paradójicamente, restituir a las letras una plenitud de significación: "La letra se abre y ofrece su tesoro oculto" (ORTIZ, 2013, p. 65). En ese movimiento, se produce una suspensión de la función referencial del discurso, patentizándose que la letra, como todos aquellos objetos en los que se detiene la mirada de Ortiz, es también un objeto fabricado por los hombres; se distingue de los demás, sin embargo, por ser el que primordialmente enrarece el presupuesto de la posesión privada de la interioridad.

Que la inteligibilidad de aquella sorpresa o conmoción infantil se alcancecuarentaaños después, comoquien despeja su vista delas partículas 
que la dificultan, sirve de señalamiento a lo que una epistemología de las ruinas es capaz de lograr. El gabinete vacío de un viejo aparato de televisión, un antiguo escritorio de madera, revistas y máquinas de una época perimida, entre tantos objetos en los que la mirada del narrador se detiene, emergen casual y repentinamente en las costas de un mundo que ya no los reconoce como propios, a la par que tipografías en desuso: "muchos objetos y obras de arte que fueron concebidos como proyecciones del futuro hoy los encontramos envejecidos, inconfundiblemente unidos a una determinada época histórica: son las ruinas del futuro" (ORTIZ, 2013, p. 105). Que se encuentren aquí deslizamientos benjaminianos procedentes de las Tesis de filosofía de la historia no debe sorprender. A su manera, como se verá, también Ortiz cepilla la historia a contrapelo.

\section{UNA PRÁCTICA DEL ESPACIO}

Al comienzo de la segunda parte del séptimo volumen de los Cuadernos se presenta un croquis de Villa Mitre, el barrio de la ciudad de Bahía Blanca donde reside Ortiz. Ubicada al sur de la Provincia de Buenos Aires, a escasos kilómetros del Mar Argentino, Bahía Blanca es uno de los más importantes centros urbanos del interior de Argentina. En los cuadernos, Villa Mitre y Bahía Blanca adquieren proyección literaria como campo de observaciones y experimentación con el lenguaje, a partir de una práctica del espacio. Las historias que compone Ortiz comienzan a ras del suelo, "al pie de la letra", evidenciando que su condición de posibilidad tiene como primer estímulo el ejercicio errático de la mirada. De manera caprichosa, el ojo se cierra, y el objeto que la mirada ha retenido permanece suspendido en un espacio abstracto, apenas por unos instantes, porque la imaginación comienza a orbitar en torno a él, anudando y desanudando el ensamble entre el objeto y su nombre: "Las cosas despiertan un relato que nos permite ubicarlas en un espacio y un tiempo, y de esta forma se vuelven materia transmisible; o acaso al revés: el hombre emite palabras que se dirigen a los objetos y de los objetos vuelven a su cuerpo para transformarlo" (ORTIZ, 2013, p. 294). El juego no tiene fin, pero es tan singular como la sensibilidad subjetiva que lo soporta, a menudo tironeada entre la melancolía y el impulso de huir del vacío mediante la certeza de existencia que puede proporcionar el gesto de escribir. Con frecuencia, también, el juego parece potenciar la amenaza de precipitar al sujeto hacia el acantilado de la locura, pero la escritura 
de lo que ha sido percibido lo mantiene gravitando en torno al mundo de los sentidos posibles: “y mientras sigo escribiendo es como si cantase una melodía para despertar, y compruebo que todavía estoy acá. Escribo, por lo tanto existo" (ORTIZ, 2013, p. 309). Escribir, para preservarse del desfondamiento, que es indiferenciación. El juego hace balbucear la lengua, como cuando Ortiz, en el Volumen V, describe el registro que hace un filósofo de la cadena de asociaciones subjetivas en torno a la descomposición de la palabra "Napostá", nombre de un curso de agua que atraviesa Bahía Blanca y ante el cual el filósofo permanece de pie, con una libreta y un lápiz en sus manos. Ese balbuceo intralingüístico, cuyo eco Ortiz encuentra en las letras "mullidas y regordetas" con las que algunas niñas se complacen en hacer carteles, rememora una experiencia natal, que aunque irrecuperable es a la vez objeto de la más denodada búsqueda:

Las mujeres tienen un vínculo casi diríamos primordial con el lenguaje: junto con la leche, los bebés paladean las primeras palabras. La lengüita que se mueve procura el alimento y se ejercita para la pronunciación. Las palabras son al mismo tiempo vida que se succiona, sonrisa de placer y adormecimiento, blancura espesa de un nombre incesantemente repetido. Esa unidad es irrecuperable. Pasamos el resto de nuestra existencia para lograr escasos segundos de una fulguración lejanamente parecida, y solo a costa de innumerables esfuerzos de concentración (ORTIZ, 2013, p. 71).

Volvamos sobre el mapa, en el séptimo volumen. A la reproducción del trazado de las calles de Villa Mitre se sobrepone una línea punteada, interrumpida por flechas que señalan la dirección en que se desplaza una bicicleta, representada con una figura bidimensional. Como los mapas de los siglos XV, XVIy XVII, esta figura no es un adorno desprovisto de utilidad: la figura de la bicicleta y la línea de puntos alternada con flechas indican el recorrido que hace posible el mapa, una práctica del espacio que es a la vez condición del relato y relativización de la mirada: "La mirada fugaz que depositamos sobre los objetos cuando avanzamos a bordo de una bicicleta es una de las cosas más livianas que se pueden concebir" (ORTIZ, 2013, p. 263). Así, se puede decir que al mapa del conocimiento geográfico, que borra las operaciones que lo hicieron posible, Ortiz opone el croquis de una poética de los desplazamientos. Estos desplazamientos, como afirma Ana Porrúa (2016, p. 2), son la ocasión para la emergencia de "una singularidad pautada por un espacio propio”, en la que los objetos azarosamente hallados motivan investigaciones sobre un mundo sepultado, "que el poeta volverá a mirar para reponer modos de producción, circuitos económicos, maneras de la cultura" (PORRÚA, 2016, p. 2), pero que también será ocasión para 
celebrar un empirismo feliz. No un empirismo de la desesperación, como el del Ireneo Funes, de Borges, sino un empirismo que permita dar el salto hacia los otros, extinguiendo la compulsión a retornar obsesivamente sobre lo mismo. Porque no solamente existe el que escribe, sino también el que lee. De aquí esas reiteradas demandas a la atención del lector, tan frecuentes en la novela del siglo XVIII, pero que desempeñan otra función en los Cuadernos de Ortiz, toda vez que no intentan restituir un lenguaje soberano y oculto (FOUCAULT, 1996, p. 78). Una demanda como esta, que es una invitación a sumarse a una causa colectiva en la que la extinción del yo concuerda con la multiplicación arbustiva del sentido, frustrando la totalización panóptica en que se instala el ojo moderno del poder, se desliza al culminar el octavo volumen:

Abro la puerta de la finísima jaula de papel y libero todas las palabras e imágenes que estuvieron encerradas en la pantalla. Se las ofrezco a ustedes, queridos lectores.

Tómenlas.

Y si se les escapan de las manos, busquen otras en sus propias vidas (ORTIZ, 2014, p. 138).

\section{EL TIEMPO VENCE A LA ORGANIZACIÓN; EL PROCEDIMIENTO A LA INSIGNIFICANCIA}

No es sencillo seguir el rastro a Ortiz en sus Cuadernos de Lengua y Literatura. El texto resulta escarpado y cuando se cree haber identificado una estructura, esta pronto se ve desestabilizada por la irrupción de antitextos. Intentando seguir una huella, los rastreadores se internan en caminos que conducen a ninguna parte y se ven obligados a volver tras sus pasos, se percatan repentinamente de haberse desplazado en círculos o bien se distraen y sólo por curiosidad -tal vez conjeturando que quizás hayan hallado una clave- se ponen a seguir un rastro nuevo. Esas exploraciones atormentadas, hasta el punto de tornarse absolutamente vanas, encuentran no pocas recreaciones en las páginas de los Cuadernos, como ocurre con el imaginario Batallón 47 que, sin razones más fundadas que el ansia repentina de ponerse en movimiento y coronar su anodina existencia con un instante de súbita gloria, camuflado en camalotes, se subleva y recorre hacia el sur el Río Paraná, sin poder evitar disgregarse en el trayecto y desaparecer (ORTIZ, 2015b, p. 104-107). Sin embargo, el episodio ficticio y la operación poética que lo constituye no exorcizan ni 
relativizan la historia social, política y económica de un país, Argentina, y del capitalismo en general; la inscriben más bien en un espacio textual anómalo que, aunque no pueda ni pretenda reclamarse inexplorado, reivindica su contribución y la de sus semejantes a una epistemología de las ruinas que sea, a la vez, ocasión de una práctica colectivista diseminante y polimorfa. Los adjetivos resultan familiares a la crítica, trillados quizás, pero no es caprichosa la impresión de que para Ortiz se trata de hacer estallar la universalidad de la ciencia, conquistada mediante la administración científica del lenguaje ("toda Utopía termina en Dictadura/en Administración (buen inicio)”), se lee en uno de los poemas incluidos en el segundo volumen), a través de la multiplicación de las versiones de los hechos, de los relatos de lo observado y de los nombres de las cosas. A este propósito responde, también, la tentativa de Ortiz de hacer manifiesta la opacidad de la letra, su factura humana, es decir, su condición de "hecho social, un espacio comunitario con su arquitectura y economía” (ORTIZ, 2013, p. 66), y que otorgando la impronta de un estudio cultural sobre la tipografía occidental moderna y europea a la segunda parte del quinto volumen de la serie, concluye por denunciar el carácter mitológico de la hipótesis que postula que la letra es apenas una "mera transcripción insignificante del sonido" (ORTIZ, 2013, p. 70).

De esta manera, el relato de la expedición desquiciada del Batallón 47 se despliega sobre los sedimentos de una época "en que los milicos se dedicaban a cagarse a palos entre sí antes de que se pusieran de acuerdo para darle a los civilachos" (ORTIZ, 2015a, p. 92), entramándose en prolongaciones que remiten a la Batalla de la Vuelta de Obligado (1845) y, más allá, a la Guerra de Troya, así como las especulaciones de un observador ante su pava retrotraen a la historia del suministro de gas en el país y a la privatización del servicio en la década de los noventas, correlativa al desmantelamiento del modelo del Estado benefactor.

La epistemología de las ruinas en la que encuentran buena parte de su impulso las investigaciones de Ortiz -aunque tal vez convendría hablar de restos y desechos antes que de ruinas, toda vez que son objetos desperdigados y en desuso los que permiten el acceso a un tiempo y a un espacio que los ilumina en su historicidad sin reducirlos a ella- produce artefactos poéticos que otorgan a las cosas una posibilidad de sobrevida, ya no como objetos funcionalizados según una dinámica del consumo, tampoco como objetos estetizados de acuerdo a una política de la nostalgia envolvente y confortable; por el contrario, la rememoración que 
despiertan los objetos ruinosos tiene como objetivo un despertar al "entre dos" de las palabras y las cosas, a la intratabilidad que lo define, para "dar el salto” y romper el círculo del eterno retorno. Una experiencia con el lenguaje, a partir de cosas desprovistas de las fantasmagorías del valor de cambio y del valor de uso, que sea una "experiencia de la apertura para dar un salto y transformarse en otra cosa” (ORTIZ, 2013, p. 89).

Es de notar que la insignificancia de las cosas espigadas por Ortiz -la carcasa de un televisor, una lata oxidada de café- obedece no tanto al transcurso del tiempo como a la colonización del tiempo por las leyes del Capital, cuya comprensión y efectos elude la evocación melancólica cuando las convierte en antigüedades para afincarlas decorativamente en un mundo que les es ajeno. Como se sabe, la destrucción de las cosas, su obsolescencia programada, no es un fenómeno residual de la acumulación capitalista; es el signo de su vitalidad y el mandato de ese ángel exterminador que se da en llamar progreso. En cambio, la melancolía de Ortiz está controlada por un procedimiento poético-literario ["Yo no he ocultado ningún procedimiento; ningún hilo permaneció escondido ante la mirada del lector" (ORTIZ, 2013, p. 191)], una "máquina de tramar", que restituye a los desperdicios un espesor histórico y cultural, pero también subjetivo. Si bien el acto de investir afectiva e intelectualmente a los objetos es característico de la especie humana, el rescate de la insignificancia que produce el procedimiento orticiano no está desvinculado de cierta introspección redentora, no porque conduzca a la autoafirmación del "yo" sino porque establece nuevas formas de ser en común, palabras y cosas, hombre y mundo: "Cada cosa (objetos y palabras) se encuentra en un nodo particular de vectores (funciones) que se cruzan y enlazan, y cuya totalidad forma una malla tupida que, de hecho, abarca el conjunto del universo" (ORTIZ, 2013, p. 151).

El tratamiento de des-cristalización de las cosas utilitariamente perimidas que propone Ortiz es productor de sentido y, en esta medida, persigue una activación de "funciones verbales y noverbales" -como indica el prospecto farmacológico adjunto a la reedición de los cuadernos I, II y III (ORTIZ, 2015a, p. 5)- capaz de combatir a dos frentes: el de la carencia de sentido y el del sentido único. Mientras el primero amenaza con una desertificación arrasadora que compromete la humanidad del hombre -y por eso, "de lo que no puede hablarse es preferible hablar" (ORTIZ, 2013, 248), el segundo agita una imaginería poblada de linchamientos, chivos expiatorios, quema de libros y caza de brujas. Para Ortiz, este último 
salta a la vista en la tipografía y la arquitectura de las construcciones "fachosoviéticas": "El poder absoluto llevado a sus últimos extremos presiona el lenguaje hasta fracturar los nexos lógicos, y las palabras se desdoblan en fantasmas esquizofrénicos, o colisionan en medio de paradojas y contrasentidos" (ORTIZ, 2013, p.94-95). Contra ambos frentes, ensayos, pruebas, máquinas y procedimientos: "Estos ejercicios no pretenden otorgar un sentido más puro a las palabras de la tribu; se conforman con encontrar, al menos, algún sentido" (ORTIZ, 2013, p. 316).

El procedimiento que se desarrolla imprevisiblemente a partir de la mirada de una cosa socialmente insignificante emula cierta estructura del despertar-abrir y cerrar los ojos, despejar la retina y cargar la imaginación, son movimientos que se reiteran en los registros de observación incluidos en los Cuadernos-, impregnada de la sensación de percibir los objetos fuera de foco, desvinculadas de la costumbre y de su función. En el despertar se aprecia cómo los objetos indeterminados llegan a ser cosas -para recuperar una diferenciación convenientemente subrayada por Remo Bodei (2013)-, es decir, nudos relacionales en los que nos encontramos involucrados sin poseer su dominio. Puede decirse entonces que el procedimiento cumple eficazmente esta tarea, de empuje contrario a la abstracción científica y a ese momento cartesiano en el que el acceso a la verdad dejó de requerir al ser del sujeto: “(...) porque establecen las conexiones entre los diversos segmentos de nuestra historia individual y colectiva, salvar las cosas de la insignificancia significa comprendernos mejor a nosotros mismos" (BODEI, 2013, p. 86).

De todos los objetos rescatados por el procedimiento de Ortiz quizás sea el yuyo el que revista la condición de paradigma. Ortiz lo define como "aquello que para el hombre carece de sentido", lo insignificante mismo (ORTIZ, 2013, p. 219). Hay que advertir, que la palabra con que se designa a eso que carece de sentido señala la intromisión de un coloquialismo en la expresión de la naturaleza de un problema poético-filosófico. Esta maniobra, que a empellones introduce aspectos ostensiblemente folklóricosdesplazandola universalidad elegantequepara sí reclamanotros términos no menos provincianos, como "hierba" o "maleza", tiñe de rareza a la enunciación científica y a su normatividad preceptiva, volviéndonos desconfiados. Sin duda, esta maniobra encuentra numerosos precedentes en la poesía argentina de los noventas, especialmente en el objetivismo ligado a una poética de los desechos, pero más específicamente, en la voluntad de intervención en el espacio público de los poetas mateístas, 
aludidos en los Cuadernos en más de una oportunidad. Seguramente, de esta voluntad, que toma "lo que hay", no para resignarse si no para provocar un despertar, se desprende la convicción de que la ciencia de palabras vegetales no habrá de subordinarse a los dictados de una monarquía depuradora de lo accidental y provisorio: "La ciencia de palabras vegetales debe ser hecha por todos” (ORTIZ, 2013, p. 283). Esta ciencia jubilosa exige poco y ofrece mucho: mirar el árbol de tal manera que seamos capaces de ver el bosque.

\section{REFERENCIAS}

BODEI, Remo. La vida de las cosas. Trad. Heber Cardoso. Buenos Aires: Amorrortu, 2013.

DE CERTEAU, Michel. La invención de lo cotidiano. I. Artes de hacer. Trad. Alejandro Pescador. México: Universidad Iberoamericana, 1996.

FOUCAULT, Michel. Nietzsche, Freud, Marx. Trad. Carlos Rincón. Buenos Aires: El cielo por asalto, 1995

FOUCAULT, Michel. “Lenguaje y literatura”. En: De lenguaje y literatura. Trad. Isidro Herrera Baquero. Barcelona: Paidós Ibérica: 1996.

MENNINGHAUS, Winfried. Saber de los umbrales. Walter Benjamin y el pasaje del mito. Trad. Mariela Vargas y Martín Simensen de Bielke. Buenos Aires: Biblos, 2013.

ORTIZ, Mario. Cuadernos de Lengua y Literatura V, VI y VII. Buenos Aires: Eterna Cadencia, 2013.

ORTIZ, Mario. Cuadernos de Lengua y Literatura VIII. Buenos Aires: Eterna Cadencia, 2014.

ORTIZ, Mario. Cuadernos de Lengua y Literatura I, II y III. Buenos Aires: Hemisferio Derecho Ediciones, 2015a.

ORTIZ, Mario. Cuadernos de Lengua y Literatura 3 1/2. La canción del poeta atrasado. Córdoba: miembro fantasma, 2015b.

PORRÚA, Ana. "Irrupción y metamorfosis: la imagen en la poesía de Mario Ortiz. Para una crítica poética”. En: Orbis Tertius. Revista del Centro de Estudios y Crítica Literaria IDlHCS/CONICET de la Facultad de Humanidades y Ciencias de la Educación de la Universidad Nacional de La Plata. Vol 21. $N^{\circ}$ 24, diciembre de 2016. Disponible en: http://www.orbistertius.unlp.edu.ar/article/view/OTv19n2oao1/6261 